University of Massachusetts Amherst

ScholarWorks@UMass Amherst

2015

\title{
Language instruction educational programs and academic achievement of Latino English Learners: Considerations for states with changing demographics
}

Francesca López

University of Arizona

Elizabeth McEneaney

University of Massachusetts - Amherst

Martina Nieswandt

University of Massachusetts - Amherst, mnieswan@educ.umass.edu

Follow this and additional works at: https://scholarworks.umass.edu/education_faculty_pubs

Part of the Education Commons

\section{Recommended Citation}

López, Francesca; McEneaney, Elizabeth; and Nieswandt, Martina, "Language instruction educational programs and academic achievement of Latino English Learners: Considerations for states with changing demographics" (2015). College of Education Faculty Publication Series. 330.

Retrieved from https://scholarworks.umass.edu/education_faculty_pubs/330 


\title{
Language Instruction Educational Programs and Academic Achievement of Latino English Learners: Considerations for States with Changing Demographics
}

\author{
FRANGESCA LÓPEZ \\ University of Arizona \\ ELIZABETH MCENEANEY \\ University of Massachusetts Amherst \\ MARTINA NIESWANDT \\ University of Massachusetts Amherst
}

\begin{abstract}
Little research currently examines language instruction educational programs (LIEPs) in states with a more recent growth of the Latino English learner population. To meet this need, the authors examined the content each of the state LIEPs, focusing chiefly on the extent to which the types of language support, as well as the stipulations associated with them, are made explicit. Using US Census data from 1970 and 2009, the authors assessed LIEPs in the context of Latino population patterns and examined the relationship between the degree to which state LIEPs emphasize bilingual education and fourth-grade Latino English learners' achievement patterns in reading, mathematics, and science achievement on the 2009 National Assessment of Educational Progress (NAEP) for all 50 US states and the District of Columbia. Latino English learners in states with a higher proportion of Latinos tend to have higher achievement outcomes when policies emphasize bilingual education, but these states also have a longer history of Latino presence. Implications for high-growth states are discussed.
\end{abstract}

Although the United States has a long history of immigration from countries spanning the globe, the dramatic growth of Latino English learners (ELs) over the past 4 decades is well documented (García and Frede 2010; Krogstad and 
Keegan 2014). Of the approximately one in five students who speaks a language other than English at home (US Census Bureau 2009), over 70\% speak Spanish as their native language (García and Frede 2010). More than 60\% of all Latino ELs, however, are concentrated in only six states: Arizona, California, Texas, New York, Florida, and Illinois (Capps et al. 2005). Accordingly, much of the body of research examining the effectiveness of language instructional education programs (LIEPs) in promoting English proficiency for English learners has customarily been examined in states with a long history of higher concentrations of Latino populations, such as Arizona (e.g., Rolstad et al. 2005) and Texas (e.g., Tong et al. 2008). ${ }^{1}$ Over the past several decades, however, several states have witnessed exponential growth in their Latino EL population (García and Frede 2010). To date, little is known about how these newer state contexts address the federal requirement of meeting the needs of Latino ELs.

In consideration of the evidence that state policies have more influence on ELs' achievement than schools (Rumberger and Tran 2010) and the rising number of states that must consider how to meet the needs of ELs, we first inspected the content of each state LIEP, examining the extent to which the types of language support, as well as any stipulations associated with them, are made explicit. Using US Census data from 1970 and 2009, we also examined the mandates in the context of Latino population patterns. ${ }^{2}$ Then, using both state LIEPs and census data, we examined whether state LIEPs are related to Latino ELs' achievement patterns in reading, mathematics, and science achievement on the 2009 National Assessment of Educational Progress (NAEP) for Latino ELs across all 50 US states and the District of Columbia. ${ }^{3}$ By understanding the achievement patterns in states with a longer history of Latino EL presence, states with recent growth can prepare accordingly.

FRANCESCA LÓPEZ, PhD, is associate professor in the educational psychology department in the College of Education at the University of Arizona. Her research examines how educational settings can promote achievement for Latino youth. ELIZABETH MCENEANEY is associate professor of teacher education and curriculum studies at the University of Massachusetts Amherst. Her current research interests include inequality of access and outcomes in STEM education and understanding how educators use data to shape instructional practice. MARTINA NIESWANDT is associate professor of science education in the Department of Teacher Education and Curriculum Studies at the University of Massachusetts Amherst. Her research utilizes mixed-methods approaches to understand the relationship between motivation, affect, and learning associated with school science concepts. 


\section{History of Federal Mandates to Meet the Needs of ELs}

The political landscape of the United States has shaped the ebb and flow of language policies. Early in our history, ideologies were purported to "justify the exploitation of enslaved African peoples" (Wiley and Wright 2004, 146) as well as to "expedite deculturation and pacification" among Native Americans (146). In 1906, Congress enacted an English language requirement for citizenship "undoubtedly in reaction to an all-time high level of immigration" (Linton 2004, 282). Despite numerous bilingual schools prior to World War I, the use of German and other foreign languages became restricted in schools "until Grades 6 to 8, when it was less likely that children would draw on their native languages" (Wiley and Wright 2004, 147). In more recent times, the antibilingual climate that tends to target Spanish-speaking populations has increased commensurately with the growing Latino population (Wiley and Wright 2004); this population increase is attributable in part to legislation "to open the nation's borders" passed by Congress in 1965 (Krogstad and Keegan 2014).

In 1968, the Elementary and Secondary Education Act included the first legislation in our recent history that focused on the rights of minority-language students: Title VII, known as the Bilingual Education Act (for a historical account of the law, see Lyons 1990). Title VII provided optional, competitive funding to school districts for research on LIEPs. Two events in 1974, however, prompted a change in the optional nature of Title VII. One was the Supreme Court's decision in Lau v. Nichols (414 U.S. 563 [1974]), which determined that the failure to provide students who do not speak English with "adequate instructional procedures" (par. 1) was a violation of the 1964 Civil Rights Act. The second was the Equal Educational Opportunity Act (EEOA), which "requires state educational agencies and school districts to take action to overcome language barriers that impede English Language Learner (ELL) students from participating equally in school districts' educational programs" (US Department of Justice, n.d., par. 6).

The 1974 amendments to the Bilingual Education Act included explicit reference to bilingual education programs that "provided instruction in English and in the native language of the student to allow the student to progress effectively through the educational system" (Stewner-Manzanares 1988, 3). Amendments also included "capacity-building efforts" that included the expansion of curricula, research, and staffing so that "schools districts could develop enough expertise to operate bilingual education programs without federal assistance" (3).

Between 1978 and 1988, successive reauthorizations of the Bilingual Education Act changed the language of the law from mandating exclusively bilingual education strategies to including immersion strategies (see Gándara and 
Rumberger 2009, 765; Ramirez et al. 1991). The capacity-building aspect of the Bilingual Education Act was reduced so that program funding was provided to support school districts for only 1 to 3 years (Stewner-Manzanares 1988). With the passage of No Child Left Behind (NCLB) in 2001, Title VII became Title III and eliminated all references to biliteracy, bilingualism, and bilingual education (Gándara and Rumberger 2009). The notion of capacity building has remained, although it is limited to the following description: "Each recipient of a grant under this subpart shall use the grant in ways that will build such recipient's capacity to continue to offer high-quality language instruction educational programs and special alternative instruction programs to limited English proficient children after Federal assistance is reduced or eliminated" (No Child Left Behind Act of 2001, Pub. L. No. 107-110, 115 Stat. 1425, 20 U.S.C. $\$ \S 6301$ et seq. [2002], Sec. 3215).

To ensure compliance with the Equal Education Opportunity Act of 1974, which "prohibited instructional programs that in effect excluded English language learners" (Moran 2011, 408), three criteria were outlined by the Fifth Circuit Court of Appeals in the Castañeda v. Pickard (648 F.2d 989 [5th Cir. 1981]) decision. The criteria were (1) LIEPs must be supported by experts in the field, (2) school districts must provide adequate resources and personnel to carry out the instructional program, and (3) the program must be evaluated and inform necessary adjustments (Moran 2011).

The first of the Castaneda criteria is supported by a vast body of research spanning several decades. Reviews of empirical studies have favored approaches that incorporate students' native language (August and Shanahan 2006; Rolstad et al. 2005; Slavin and Cheung 2005), approaches sometimes known as additive (Lambert 1985). Nevertheless, in the late 1990s and early 2000s, California, Arizona, and Massachusetts replaced bilingual education with Structured English Immersion (SEI) after proponents of SEI promulgated its superiority to effectively transition ELs to English fluency (e.g., Crawford 1997; Rossell 2002). ${ }^{4}$ Although one of the pervasive limitations cited in reviews examining the effectiveness of LIEPs is the absence of randomized studies, researchers utilizing random assignment have found that bilingual approaches do not hinder English proficiency development (Slavin et al. 2010; Tong et al. 2008).

Despite evidence that bilingual approaches not only do not impede English acquisition (Slavin et al. 2010) but are also associated with better achievement outcomes than English-only approaches (Umansky and Reardon 2014), Arizona, California, and Massachusetts replaced earlier mandates favoring bilingual approaches with Structured/Sheltered English Immersion (SEI), a term that had not been "in current use in the language education profession but is a confusing combination of terms" (Krashen 1997). Indeed, the confusion with terminology was equally unclear to the teachers charged with its implementation in classrooms (Wright and $\mathrm{Pu} 2005)$. 
The lack of appropriate funding, the second criterion in Castañeda v. Pickard, has resulted in lawsuits in almost every state (Horsford and Sampson 2013). Although the replacement of bilingual education with SEI began in California, Arizona is the among the most visible in facing challenges rooted in accountability to the second criterion, with a federal district court decision that "had begun fining Arizona $\$ 500,000$ a day for failing to respond to court orders to increase funding for EL education in a way that reflected the actual needs of the students" (Gándara and Orfield 2012). The third criterion, which is closely tied to the first, reflects that the matter of how to ensure equitable educational opportunities for Latino ELs in the United States persists as "one of the most volatile questions in American education" (Cummins 1992, 91). The experts that support the program are chosen more often on the basis of ideology than evidence.

To illustrate, proponents of SEI have misrepresented the sentiments of noted language acquisition scholars to create an image of support for SEI and thus be in compliance with the first criterion outlined by Castañeda v. Pickard. A research summary presented by the Arizona Department of Education $(2007,1)$ asserts that August and Hakuta (1997) "concluded that little scientific research had been conducted with school-age ELs and expressed their concern about how 'politics have constrained the development of sound practice and research in this field." "The politics August and Hakuta referenced, however, were the very ones that have maintained SEI in Arizona (as well as California and Massachusetts). Indeed, in a declaration to the State of California, Hakuta explicitly states that citations of his and other scholars' work "misrepresent its main findings" (supplemental declaration by expert witness Kenji Hakuta to the State of California for Eliezer Williams, et al., v. State of California, et al. [2000]). He further asserts that "there is no defensible theory base to the programs prescribed by Proposition 227" and "outcomes for students placed in programs similar to those proposed by Proposition 227 are alarmingly poor, hardly worthy of state-wide prescription, and harmful to students." ${ }^{5}$ Despite Hakuta's declaration, SEI continues to be implemented in Arizona, California, and Massachusetts, with his work cited by the Arizona Department of Education as support for SEI. Notably, even though SEI replaced bilingual education in only three states, California policy has been found to "often have repercussions for the rest of the nation" (Gándara 2012, 219). Accordingly, the discrepancies in research and policy merit attention, particularly for states that are considering LIEPs for their growing EL population.

\section{State Policies}

The No Child Left Behind Act sets the standards to which each state must comply. Among the NCLB requirements that are most salient for ELs are the 
assessment of English proficiency and progress in English language acquisition. NCLB does not, however, stipulate the type of LIEP used by states. As a result, there are various language instruction programs based on dissimilar philosophical frameworks and potentially dissimilar instructional opportunities for the acquisition of English across the 50 US states (see Cummins 1992). Accordingly, Linton (2004) asserts: "It is impossible for a state to be neutral toward language... . The state's choices influence the value of the linguistic capital of various groups in the population, including immigrants whose native language differs from that of the host country" (279).

Some states mandate bilingual education explicitly (e.g., New Mexico, Texas, and Wisconsin). There is wide variability in bilingual programs both within and across states, including early exit, late exit, or two-way models. Despite the variability, all bilingual programs incorporate instruction in students' native language as students also acquire English. Other states mandate SEI (the model that replaced bilingual education in Arizona, California, and Massachusetts). SEI is sometimes referred to as English-only instruction because it does not incorporate native language support; however, SEI is required to include some kind of structured support due to the federal recognition of EL students as having particular learning needs (Lau v. Nichols). The main component of SEI is maximizing instruction in English by using second-language acquisition strategies (i.e., using English at a level appropriate for students; Clark 2009). There are also states that are explicit in embracing various LIEPs, allowing both SEI and bilingual education (e.g., Colorado, Nevada, and Florida). Still other states have no mandates, deferring instead to NCLB requirements that omit explicit mention of the kinds of LIEPs that should be used to meet the needs of ELs (e.g., Kentucky and South Carolina). In these states, decisions on LIEPs are often left to each local educational agency (LEA). Regardless of the mandates (or lack thereof), however, states receiving Title III funds (and, notably, all states receive Title III funds) must provide evidence that the LIEPs chosen to address the linguistic needs of ELs are supported empirically. Nevertheless, only states with higher proportions of Latinos tend to be examined in the extant research, despite changing demographics nationwide.

Not only do states vary substantially in their mandates on LIEPs but there is also much variation in the ways these programs are defined and implemented and the degree to which they deviate from prescribed implementation (see Collier and Thomas 2004). Nevertheless, LIEPs - while perhaps not directly related to ELs' achievement - contribute to the ways LEAs delineate compliance for the educational experiences of linguistic minority populations. For example, in their examination of achievement gaps between ELs and nonELs on the 2005 reading and mathematics NAEP across all 50 states and the District of Columbia, Rumberger and Tran (2010) found that whereas 15\%$20 \%$ of the variability in non-EL student achievement is attributable to state 
policies, state policies explain close to $40 \%$ of the variability in achievement gaps for ELs. They assert: "This finding suggests that states have more control over the size of the EL achievement gap than over their overall achievement levels and that state policies - such as whether to provide EL students with specialized instruction ... could help reduce the gap" (99).

Although a focus on achievement disparities often ignores the problematic assumptions of gauging ELs' achievement against native English speakers' performance on assessments in English, Rumberger and Tran's research suggests that the magnitude of disparities are acquiescent. Notably, the researchers found that the achievement gap in Massachusetts was particularly large despite average scores that are among the highest in the nation, suggesting that "factors that improve overall student performance may not reduce the achievement gap" (2010, 90). The finding that a rigorous curriculum that increases overall student achievement is insufficient to address the educational needs of ELs underscores the exigency in examining ways in which Latino ELs' needs are distinct from the general student population, while moving beyond an examination of how quickly ELs can acquire English.

\section{Methodology}

\section{Content Analysis of State LIEPS}

To add to our understanding about the ways all states address the needs of ELs, we conducted an emergent content analysis (Neuendorf 2002) to assess the degree to which each state's educational policy emphasizes bilingual education. The text of current state policies was gathered from information compiled by the NCELA and all state Title III offices (Batalova and McHugh 2010; National Center on Immigrant Integration Policy). ${ }^{6}$ If the text of the policy was not present on the state's main Title III page, the website was searched using terms such as "ELL" and "limited English proficient." We confirmed the language of the mandates with state education agency websites, as well as the Title III coordinator for each state. States that do not have an explicit mandate default to NCLB requirements, which removed all references to bilingual education that were in place in the Elementary and Secondary Education Act prior to 2001 (Wright 2005). We reviewed each of the mandates and expanded a rubric from prior work (López and McEneaney 2012). The coding rubric that resulted is reflected in table 1 .

To assess reliability of the coding of bilingual education emphasis, two doctoral-level students were asked to code the de-identified laws (i.e., state names and identifying information was removed). The scorers were provided 
Language Instruction Educational Programs and Academic Achievement

TABLE 1

Scoring Rubric for Bilingual Emphasis in LIEPs

\begin{tabular}{lc}
\hline Score & Rubric \\
\hline 0 & $\begin{array}{c}\text { No bilingual education or use of students' language is allowed. If there are } \\
\text { waivers permitted, the waivers preclude the need for bilingual education }\end{array}$ \\
1 & $\begin{array}{c}\text { No bilingual education or use of students' language allowed, but there are } \\
\text { waivers and/or exceptions made with parental request }\end{array}$ \\
2 & $\begin{array}{l}\text { Various LIEPs are explicitly presented as options, but they exclude bilingual } \\
\text { education }\end{array}$ \\
3 & $\begin{array}{c}\text { Any LIEP can be used, but bilingual education is used rarely if at all } \\
\text { Any LIEP can be used. Bilingual education is explicitly mentioned and/or used }\end{array}$ \\
5 & $\begin{array}{c}\text { Bilingual education is mandated in cases where staffing is available and/or a } \\
\text { minimum number of students are enrolled in the same school }\end{array}$ \\
6 & $\begin{array}{c}\text { Bilingual education is mandated in cases where a minimum number of students } \\
\text { are enrolled in the district (or LEA) }\end{array}$ \\
7 & Bilingual education is mandated for all students (including non-ELLs)
\end{tabular}

NOTE.-LIEP = language instruction educational program; LEA = local educational agency; ELL = English language learner.

the following rules for scoring: "use the rubric to assign a code to each state mandate." The three sets of scores (which included one investigator's scores) showed high interrater reliability, with $95.7 \%$ perfect agreement across all pairs of ratings. A measure of reliability recommended for content analysis and adjustable for ratings at different levels of measurement is Krippendorff's alpha (Hayes and Krippendorff 2007; Iacobucci et al. 2001). Our ratings resulted in an alpha of .992 (assuming ratings are ordinal, with alpha for perfect agreement equal to 1.0). These final codes were verified with information on the kinds of programs available for ELs provided by each state for Annual Yearly Progress, available through reports compiled by the National Center for English Language Acquisition. Detailed descriptions of the state policies are presented in the appendix (available online). To examine LIEPs in terms of the change in the proportion of Latinos in each state, we also used US Census Bureau information from 1970 and 2009. We present the scoring for the LIEPs, the proportion of Latinos in 1970 and 2009, and the percent change in table 2.

\section{Achievement Pattern Data}

To examine achievement patterns across all 50 states and the District of Columbia, we used restricted-license data from the 2009 grade 4 NAEP in reading, mathematics, and science. ${ }^{7}$ NAEP assessments are increasingly viewed as legitimate, common metrics of what students know and can do, with some suggesting using NAEP as a means to check the validity of individual state

424 American Journal of Education 
assessments (Stoneberg 2007). The NAEP program informs the "Nation's Report Card," which was first instituted in 1969 and collects extensive data on a national- and state-representative sample of schools; students in grades 4,

8 , and 12; and their teachers, on a biennial basis. In the present study, we limited NAEP analyses to fourth grade because of our focus on state LIEPs, which tend to address the needs of elementary-age students (i.e., bilingual programs are rare in the secondary grades regardless of state policy). In part, this is because ELs at the secondary level tend to have different needs than those of their younger peers, with many caught in the cycle of being long-term ELs (see Callahan 2005).

The specific data used in the present study consisted of measures at two levels of analysis available in NAEP: the student and his or her school. NAEP data are obtained from a complex cross-sectional sampling scheme with multistage sampling at the levels of geographic area, schools, and students. The NAEP sample design is specified to draw samples that are not only representative of the nation but also of individual states - a critically important feature, given that our research question focused on achievement (e.g., Lee 2006). Thus, NAEP includes a large representative sample of Latino EL students for all states, which provided sufficient power to conduct the analyses (Maas and Hox 2004; Mok 1995).

\section{Sample}

Our achievement analyses included all fourth-grade Latino EL students attending public schools who took the NAEP reading, mathematics, and science assessments in all 50 states and the District of Columbia in 2009. There are approximately 2,500 schools and 11,000 Latino fourth-grade ELs (weighted $\mathcal{N}$ ) across the three subjects in each year. Descriptive statistics for each of the 2009 NAEP subject data sets in the present study are presented in table 3 . The supplemental gap analysis at the state level was based on reported 2009 state NAEP achievement test means (NAEP Data Explorer, available at http:// nationsreportcard.gov/data_tools.asp) for Latino non-ELs who are not lunchprogram eligible and for Latino ELs who are lunch-program eligible.

\section{Variables}

\section{Level 1: NAEP Student-Level Variables}

Reading, mathematics, and science achievement.-We used NAEP reading, mathematics, and science achievement as dependent variables. NAEP relies on item 
TABLE 2

States by Percent of Growth in Latino Population since 1970 and Current State Ranking for Bilingual LIEP Emphasis

\begin{tabular}{|c|c|c|c|c|}
\hline State & Bilingual Emphasis & 1970 & 2009 & $\%$ Growth \\
\hline$\overline{\mathrm{NM}}$ & 7 & 30.3 & 44.9 & 148 \\
\hline AK & 6 & 1.5 & 6.1 & 407 \\
\hline CT & 6 & 2.2 & 12.0 & 545 \\
\hline NJ & 6 & 4.0 & 16.3 & 409 \\
\hline $\mathrm{TX}$ & 6 & 16.4 & 36.5 & 222 \\
\hline WA & 6 & 1.7 & 9.8 & 578 \\
\hline IL & 5 & 3.5 & 15.3 & 436 \\
\hline MI & 5 & 1.7 & 4.1 & 244 \\
\hline NY & 5 & 7.4 & 16.7 & 225 \\
\hline WI & 5 & 1.4 & 5.1 & 363 \\
\hline $\mathrm{CO}$ & 4 & 10.2 & 20.2 & 198 \\
\hline DC & 4 & 2.0 & 8.6 & 432 \\
\hline DE & 4 & 1.5 & 6.8 & 451 \\
\hline $\mathrm{FL}$ & 4 & 6.0 & 21.0 & 350 \\
\hline $\mathrm{HI}$ & 4 & 3.2 & 8.7 & 273 \\
\hline IA & 4 & .7 & 4.2 & 601 \\
\hline ID & 4 & 2.3 & 10.2 & 445 \\
\hline IN & 4 & 2.2 & 5.2 & 237 \\
\hline KS & 4 & 2.4 & 9.1 & 380 \\
\hline LA & 4 & 1.9 & 3.4 & 177 \\
\hline $\mathrm{MD}$ & 4 & 1.2 & 6.7 & 556 \\
\hline $\mathrm{MN}$ & 4 & 1.0 & 4.2 & 415 \\
\hline $\mathrm{MO}$ & 4 & 1.3 & 3.2 & 247 \\
\hline MS & 4 & .7 & 2.2 & 320 \\
\hline MT & 4 & .9 & 3.0 & 331 \\
\hline $\mathrm{NG}$ & 4 & .9 & 7.4 & 826 \\
\hline $\mathrm{OH}$ & 4 & 1.2 & 2.6 & 219 \\
\hline OK & 4 & 2.0 & 7.7 & 383 \\
\hline OR & 4 & 1.1 & 11.0 & 998 \\
\hline $\mathrm{PA}$ & 4 & .9 & 4.8 & 530 \\
\hline RI & 4 & .8 & 11.6 & 1454 \\
\hline UT & 4 & 3.2 & 12.0 & 376 \\
\hline $\mathrm{AL}$ & 3 & 1.1 & 2.9 & 263 \\
\hline $\mathrm{KY}$ & 3 & 1.4 & 2.4 & 171 \\
\hline ME & 3 & .2 & 1.3 & 640 \\
\hline ND & 3 & .4 & 2.1 & 515 \\
\hline $\mathrm{NE}$ & 3 & 1.4 & 7.9 & 563 \\
\hline NV & 3 & 4.2 & 25.7 & 612 \\
\hline $\mathrm{SC}$ & 3 & .5 & 4.1 & 822 \\
\hline SD & 3 & .4 & 2.6 & 653 \\
\hline WY & 3 & 4.2 & 7.7 & 184 \\
\hline GA & 2 & 1.0 & 8.0 & 802 \\
\hline $\mathrm{TN}$ & 2 & 1.3 & 3.7 & 286 \\
\hline VT & 2 & .4 & 1.4 & 345 \\
\hline WV & 2 & .5 & 1.1 & 228 \\
\hline
\end{tabular}


López, McEneaney, and Nieswandt

Table 2 (Continued)

\begin{tabular}{lcrrc}
\hline State & Bilingual Emphasis & 1970 & 2009 & \% \\
\hline CA & 1 & 11.9 & 36.6 & 308 \\
MA & 1 & 1.2 & 8.6 & 714 \\
AR & 0 & 1.3 & 5.6 & 430 \\
AZ & 0 & 15.0 & 30.1 & 201 \\
NH & 0 & .3 & 2.6 & 880 \\
VA & 0 & .9 & 6.8 & 760 \\
\hline
\end{tabular}

NOTE.-LIEP = language instruction educational program.

SouRCE.-US Census Bureau (Gibson and Jung 2002) for 1970 proportion of Latino population; US Census Bureau 2009 for 2009 proportion of Latino population.

response theory (Lord 1980) and uses matrix sampling from a total of approximately 150-200 items, varying across subjects and grade levels. Each participating student answers only a subset of the achievement items, with the testing portion of the assessment taking about 50 minutes for each subject. NAEP uses marginal maximum likelihood and conditioning techniques to generate five plausible values that represent an estimate of the student's achievement in a particular subject had he or she answered all of the items and not merely a subset (Mislevy et al. 1992). We provide more detail about NAEP variables in the appendix.

\section{Level 2: Student-Level Control Variables}

Student lunch program status (0-2).-We used student's eligibility for the federal National School Lunch Program as a measure of socioeconomic status (the only one provided by NAEP), coded on a scale of $0-2$, with $0=$ not eligible, $1=$ eligible for reduced-price lunch, and $2=$ eligible for free lunch.

Female (0-1).- A dummy variable indicating female gender (1) was included in the analysis, with the baseline of male $=0$.

Individualized education program (IEP) (0-1).- Another dummy variable was used to control for whether school records showed that the student was in a special education program as evidenced by the filing of an IEP, where $1=$ student had an IEP.

English reading and writing proficiency (0-3.).- NAEP has sought to be more inclusive of ELs in recent administrations, reducing problems of sample selection bias that concerned previous analyses using NAEP (Carnoy and Loeb 2002). Various accommodations were possible across reading, mathematics, and science for the 2009 administration, resulting in an exclusion rate of only one out of 10 EL fourth graders (NAEP 2010). Additionally, NAEP includes 


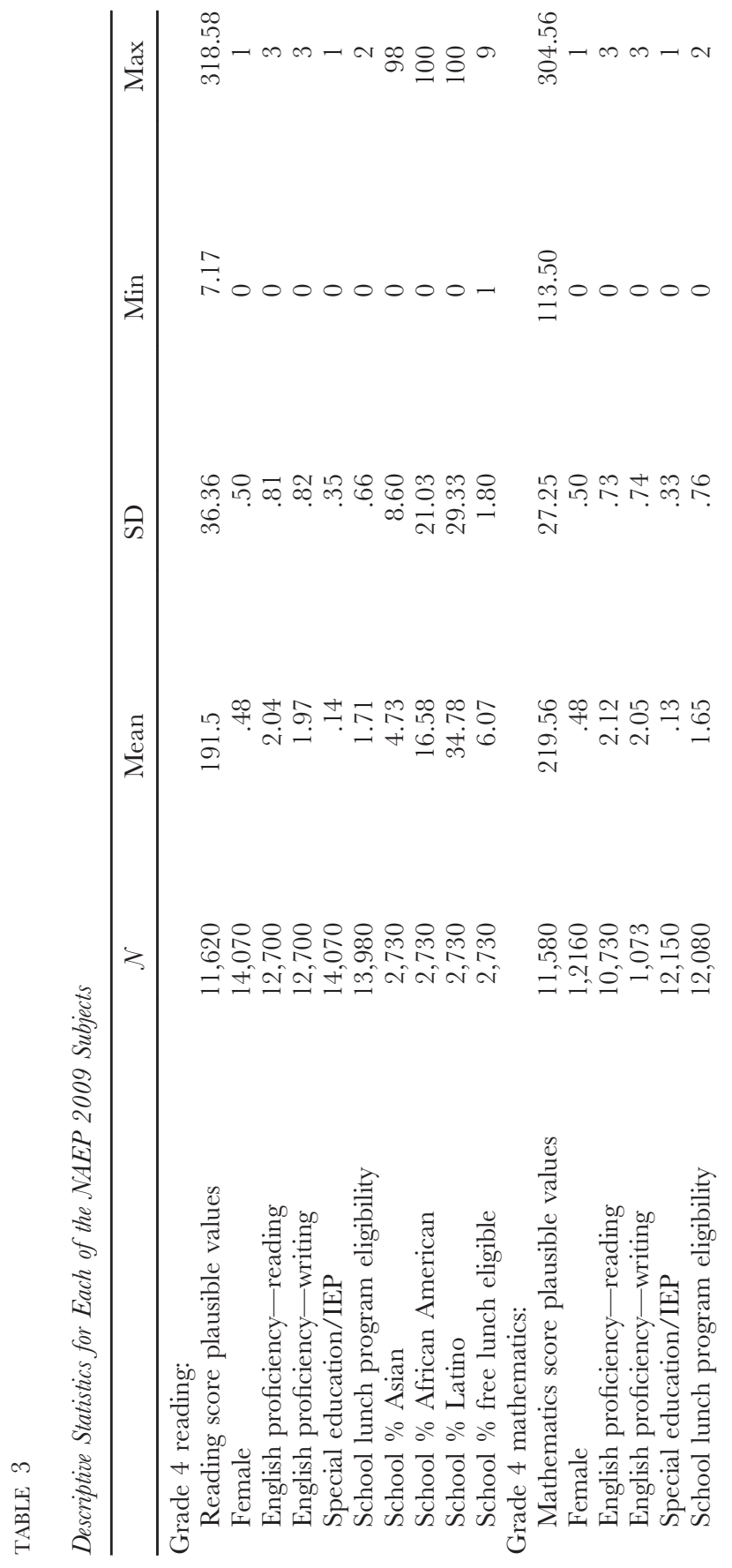

428 


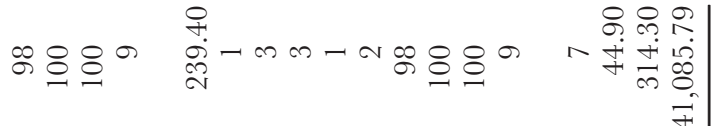

$$
\begin{aligned}
& \text { ま }
\end{aligned}
$$

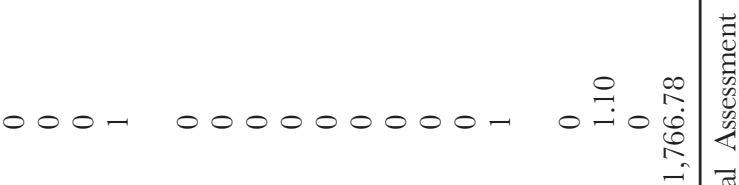

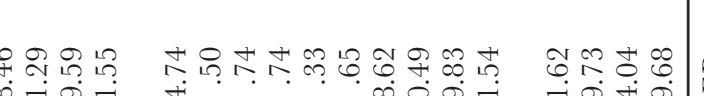

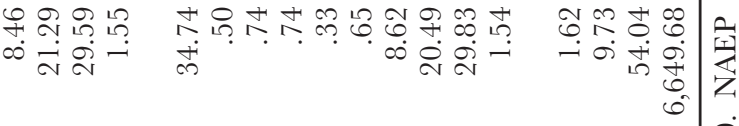

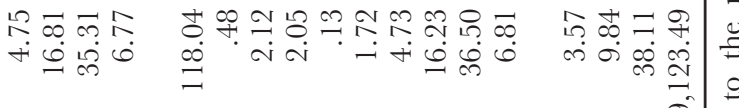

$$
\begin{aligned}
& \text { के }
\end{aligned}
$$

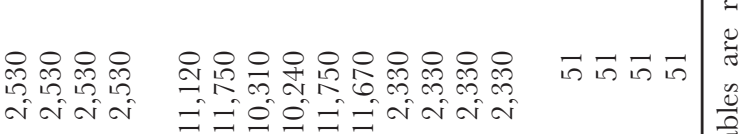

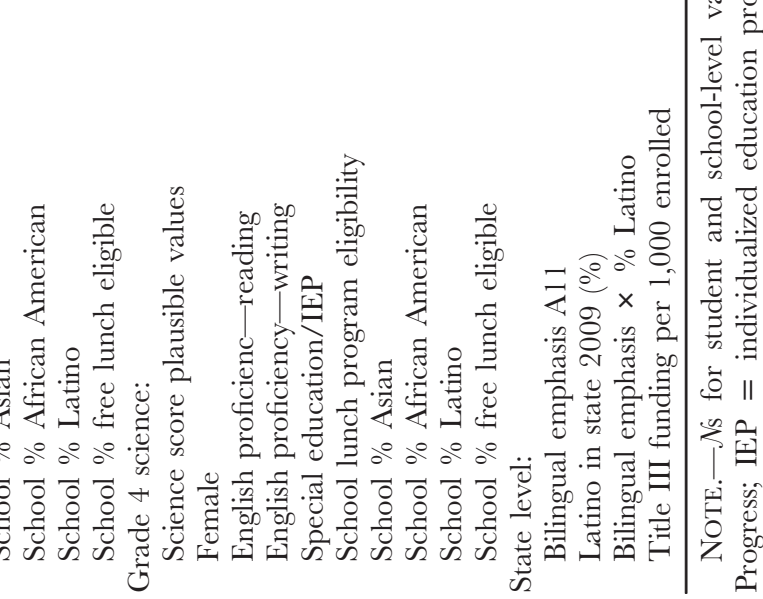


information about whether a student is currently an EL, formerly an EL, or not an EL. Although one of the key indicators of the effectiveness of LIEPs has included the reclassification rates of ELs to English proficient status, there are pervasive issues with this practice (Gándara and Merino 1993, 333). To reduce issues introduced by the variation in the way states determine reclassification of ELs to non-ELs, we included students who were classified as ELs at the time of testing as well as those who had been classified as EL prior to testing ("formerly EL"). To account in part for the diversity in English proficiency introduced by including both ELs and formerly ELs in the sample, we included an independent measure of English reading and writing proficiency, though we acknowledge that achievement tests in all three subjects are additionally measures of English reading and writing proficiency (see Solano-Flores and Trumbull 2003). Ratings reported in NAEP regarding students' English proficiency include $0=$ no proficiency, $1=$ beginning proficiency, $2=$ intermediate proficiency, and $3=$ advanced proficiency.

\section{Level 3: School-Level Control Variables}

Percent racial/ethnic minority (0-100).- For each school, we included the percentage (provided by NAEP) of enrolled students who are Asian, African American, and Latino.

Percent eligible for free/reduced lunch (1-9).- To control for the contextual impact of socioeconomic status at the school level (Porfeli et al. 2009; Wilson 1987), we included the percentage of enrolled students who are eligible for the federally funded free or reduced-price school lunch program. For a small proportion of schools that had missing data on the percentage of students eligible for free lunch but reported the percentage of students eligible for Title I program services, we used regression analysis to estimate the percentage of students eligible for free lunch based on the percentage eligible for Title I, with $r$ ranging from +.46 to +.48 for schools in the various subject data sets. Based on school records, NAEP uses the following categories: $1=0 \%, 2=1 \%-5 \%$, $3=6 \%-10 \%, 4=11 \%-25 \%, 5=26 \%-34 \%, 6=35 \%-50 \%, 7=51 \%-$ $75 \%, 8=76 \%-99 \%$, and $9=100 \%$.

\section{Level 4: State-Level Variables}

Bilingual education emphasis of state LIEP policy (0-7).- - To examine the relationship between LIEPs and Latino ELs' achievement, we used the coding developed for the bilingual education emphasis of LIEP policy already described. 
Proportion of Latino residents in each state.-We included the proportion of Latino residents in each state $(1 \%-46 \%)$ reported in 2008 (US Census Bureau 2012).

Per-EL Title III spending.-Another potentially important aspect of the implementation of the specific language instruction program involves financial resources. The federal government's primary means for funding K-12 language instruction programs is through Title III grants to the states. State departments of education must apply for such grants in a competitive process, and so Title III funding can also be seen as a measure of state effort to bolster school-based language instruction programs. Information on Title III funding provided to each state for various years is available through the US Department of Education.

\section{$\mathcal{N A E P}$ Analyses}

We estimated a series of three level intercepts as outcomes models (one for each subject) in HLM (hierarchical linear modeling; Luke 2004), assuming that the level 1 (student-level) intercept varies across schools (level 2) and states (level 3), while the slopes of control variables at level 1 and level 2 do not. Other effects were estimated as fixed, such as bilingual education emphasis in LIEP and per-EL-student Title III funding (level 3). To examine whether Latino presence in a state moderates the relationship between the extent to which LIEPs reflect bilingual programs and student achievement, we ran a second set of HLM models with a modified set of level 3 variables that included the interaction term.

SPSS version 20.0 was used to manage and clean the data. To address the design effects inherent in the complex sampling (Raudenbush and Bryk 2002; Skinner et al. 1989; Snijders and Bosker 1999), we used AM statistical software to calculate descriptive statistics and HLM 6.0 to estimate the series of three-level models. Given the stratified sampling and to adjust for nonresponse, we applied weighting at the student and school levels (Johnson 1989; Zwick 1992).

\section{Gap Analysis}

Our primary analyses focused solely on the achievement patterns of ELs. As a final analysis, we conducted an additional OLS regression analysis to assess the relationship between bilingual emphasis in state LIEPs and the achievement disparities between Latino students who are both EL and meet eligibility for free or reduced lunch and their Latino peers who are not ELs and do not 
meet eligibility for free or reduced lunch. We conducted this analysis only for states meeting reporting criteria using data available in the NAEP Data Ex$\operatorname{plorer}(\mathcal{N}=31$ states for reading, $\mathcal{N}=32$ states for mathematics, $\mathcal{N}=28$ states for science).

\section{Limitations}

NAEP samples are carefully drawn so that they are representative of student achievement at the state level and are the only achievement measure available when comparing achievement across all 50 states. NAEP data, however, are cross-sectional and, as such, preclude the ability to examine the same students over time. This limitation prevents an examination of how state policies might influence ELs achievement across students' K-12 trajectories. Other methods, including panel analysis (Finkel 1995), can address some of the issues inherent in cross-sectional data; however, analyses using NAEP are limited to those that consider the five plausible values used in constructing achievement estimates at the state level.

Another limitation is that NAEP lacks important information for examining the ways LIEPs are related to EL student outcomes. For example, NAEP does not include information about student mobility. This limitation prevents an examination of the extent to which participating students had received instruction in a different state prior to participating in NAEP. Also excluded from NAEP are prior achievement scores, Latino ELs' time in the United States, and generational status - key variables in the examination of achievement for Latino ELs. Such controls would be necessary to more accurately examine the relationship between language policies and academic achievement among EL students and thus should be addressed by large-scale data collection efforts.

\section{Results}

\section{State LIEPS}

The four states with education policy prohibiting bilingual education resulted in the lowest ranking (according to the rubric provided in table 1): Arizona, Arkansas, New Hampshire, and Virginia. Arizona's language policy has received much attention, which corresponds to the fact that Arizona's state population has historically had a relatively large proportion of Latinos (from 15\% in 1970 to over $30 \%$ in 2009). Three other less Latino-dense states with Latino populations that range between $3 \%$ to $7 \%$ of the total population also have 
quite restrictive language education policies. For example, Arkansas policy states, "the basic language of instruction in the public school branches in all the schools of the state, public and private, shall be the English language only," as well as "any person violating the provisions of this section shall be guilty of a violation and upon conviction shall be fined not to exceed twenty-five dollars (\$25.00), payable into the general school fund of the county." Virginia also scored a zero on our rubric, with a policy asserting that "school boards shall endeavor to provide instruction in the English language which shall be designed to promote the education of students for whom English is a second language." Virginia's policy further asserts that Castañeda v. Pickard is not binding precedent because it is not in Virginia's jurisdiction. The two states that received a coding of " 1 " were California and Massachusetts, with policies similar to those in Arizona but with caveats that allow for bilingual education.

Four states' policies explicitly mention the kind of LIEPs they allow but exclude bilingual education: Georgia, Tennessee, Vermont, and West Virginia. Tennessee provides detailed information on appropriate staffing ratios and lists nine approved LIEPs — none of which includes bilingual education. Fourteen states default to NCLB's requirements (see table 2). With the exception of Nevada (with over $25 \%$ of the population identifying as Latino), states without any explicit mandate also have lower proportions of Latinos (from just over $1 \%$ to almost 8\%). Nevertheless, growth since the 1970s has increased twofold to eightfold, which may suggest apathy toward a quickly growing segment of the student population. The largest segment of states $(\mathcal{N}=21)$ are explicit in the kind of LIEPs mentioned in their policies and do include bilingual education among the allowable options. These states, however, do not reflect a pattern in terms of Latino presence. Some states have a relatively low proportion of Latinos: Mississippi, Ohio, and Montana are all under 3\%. Others, however, have a larger presence. The Latino population in Colorado and Florida, for example, represents over $20 \%$ of the total population. Earlier demographics also are not reflective of policies. In 1970, 13 of the 21 states had less than $3 \%$ of their population identify as Latino. Moreover, there is large variability in the growth patterns across these states. Louisiana has seen a $177 \%$ increase in the Latino population over the past 4 decades, whereas Rhode Island's increase is more than $1,400 \%$.

Only four states have LIEP policies that mandate bilingual education when a minimum number of students in a grade level within the same school share a native language: Illinois, New York, Michigan, and Wisconsin. Illinois has witnessed the largest growth in the Latino population among the four states with over a 400\% increase since 1970 and is noteworthy for another reason. Beginning in July of 2014, Illinois is the first state to extend the bilingual mandate to public preschools (Zehr 2010). Another five states also mandate bilingual education when a minimum number of students in a grade level share a

MAY 2015 
native language but go beyond this requirement to mandate bilingual education when there are a minimum number of students in a district (or LEA) who share a native language. These states are Alaska, Connecticut, New Jersey, Texas, and Washington. Alaska has the lowest proportion of Latinos among these five states but is among the 10 states with the highest proportion of ELs in public schools (National Center for Education Statistics 2013). The remaining four states have Latino populations between $10 \%$ and $35 \%$, all with growth between $400 \%$ and $600 \%$ (except for Texas, with over $200 \%$ growth) since 1970. The only state in the nation to mandate bilingual (and multicultural) education for all students, New Mexico, reflects the highest proportion of Latinos (45\%) - a rank also held in 1970. It also boasts the first bilingual education law in 1969 and the first Native American Language and Culture Certification for teachers (NMPED 2004).

\section{Achievement Patterns}

In our examination of the relationship between bilingual LIEP policy emphasis and achievement of fourth-grade Latino EL students in 2009 NAEP, high intraclass correlations across all three subjects, representing the proportion of variance between schools and the proportion of variance between schools and between states, are relatively high, around .25, justifying the three-level hierarchical linear models. In the first set of models, although the models are a substantially better fit than the null models for all subjects $(p<.01)$, bilingual emphasis in LIEPs and the relative size of the Latino population in states were not found to be related to fourth-grade Latino ELs' achievement in any of three subject areas, whereas the relative size of the Latino population in states was significantly negatively related to the NAEP achievement of Latino ELs in all subject areas (see the appendix).

In the second set of analyses, all state-level, school-level, and individuallevel variables were retained from the previous analyses; at the state level, however, we added the interaction term (the product of bilingual emphasis of states' LIEPs and percent Latino in each state). For all subjects, there was an overall proportional reduction of error compared to the null model $(p<.01)$. In these models, we found that the interaction term of bilingual emphasis in LIEPs and Latino presence in a state was related to fourth-grade Latino ELs' achievement in all three subject areas. In all three subject areas, the relationship between bilingual methods in LIEPs and Latino EL achievement tends to be more pronounced in Latino-populated states (see figs. 1-3 for depictions of the interaction effects across the three subject areas). Results are presented in table 4 . 


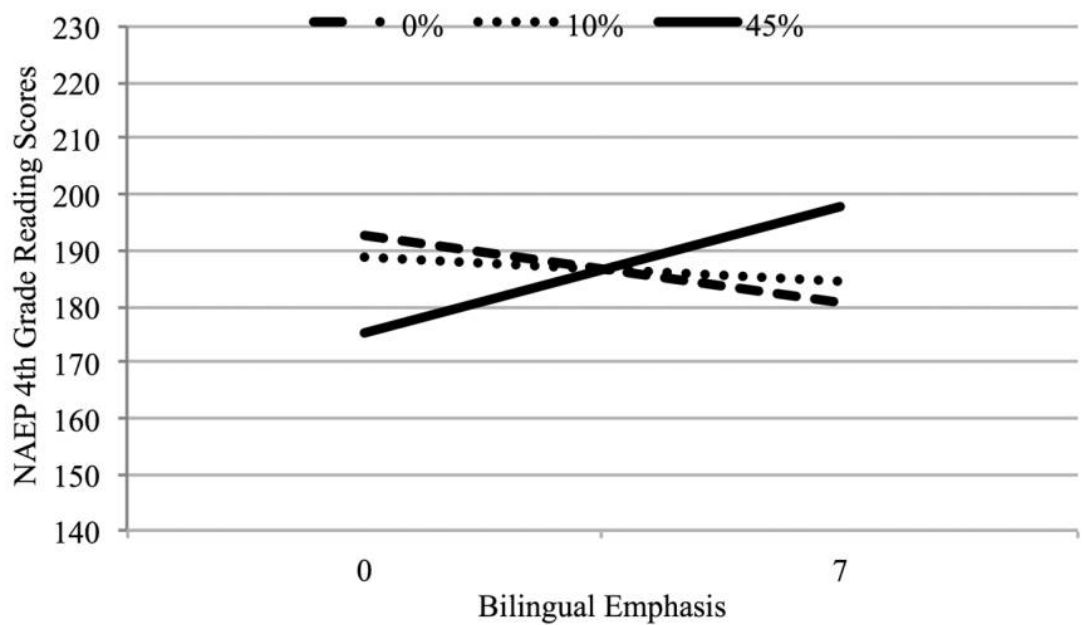

FIG. 1.- Interaction effects on fourth-grade NAEP reading for varying levels of bilingual emphasis $(0-7)$ and proportion of Latino population in state $(1 \%-45 \%)$.

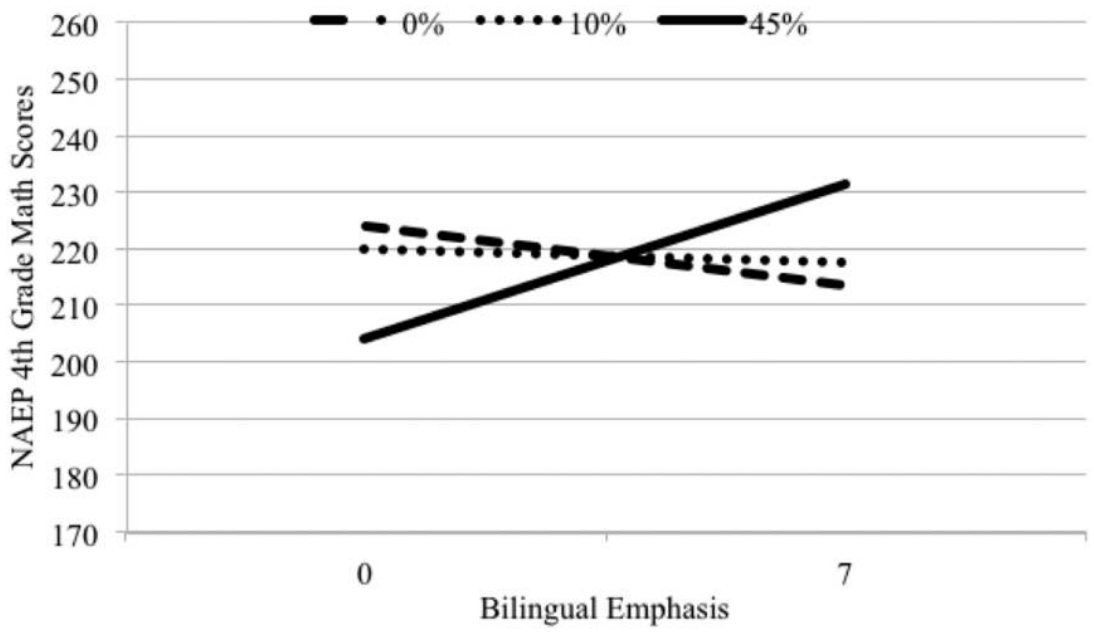

FIG. 2.- Interaction effects on fourth-grade NAEP mathematics for varying levels of bilingual emphasis $(0-7)$ and proportion of Latino population in state $(1 \%-$ $45 \%)$. 


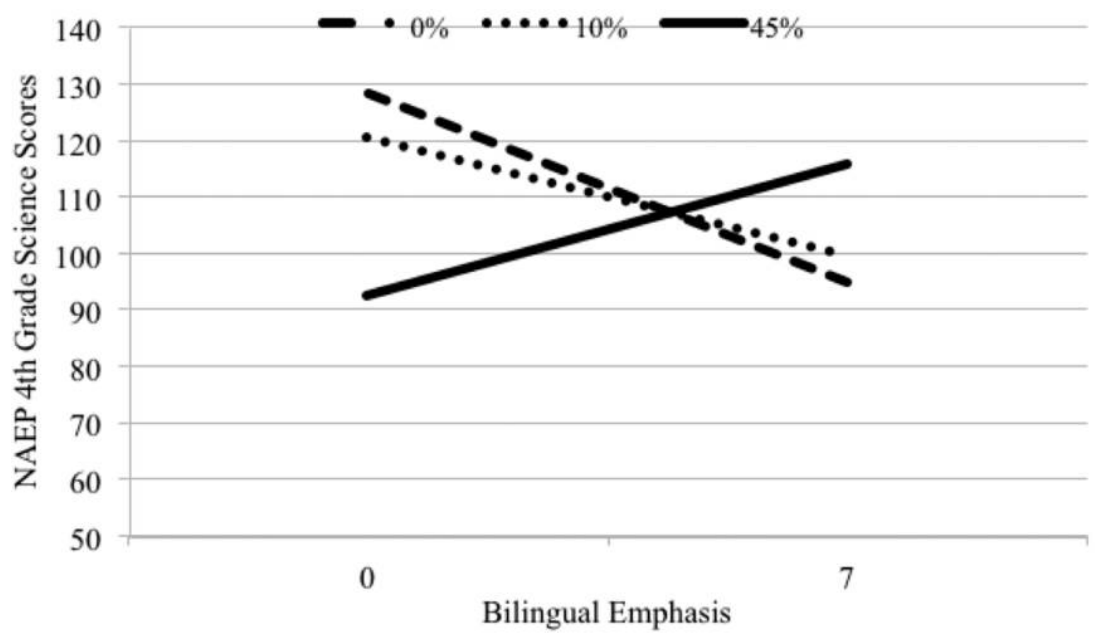

FIG. 3.-Interaction effects on fourth-grade NAEP science for varying levels of bilingual emphasis $(0-7)$ and proportion of Latino population in state $(1 \%-45 \%)$.

To illustrate the findings of the second set of analyses, Latino ELs in New Mexico (a state with the highest bilingual emphasis score of seven and approximately $45 \%$ Latino population) would tend to score about 17 points higher on the NAEP reading test (out of 500 possible points) than similar students in Arizona (a state with the lowest bilingual emphasis score of zero and proportion Latino of about 30\%). In other words, Latino ELs in New Mexico scored nearly half a standard deviation higher than Latino ELs in Arizona in the 2009 NAEP reading, holding all other effects constant. For mathematics, Latino ELs in New Mexico scored approximately 20 points higher than Latino ELs in Arizona (about three-fourths of a standard deviation in math achievement scores) and 11 points higher in science (approximately one-third of a standard deviation in science achievement scores).

Title III funding was quite highly correlated $(r=.75)$ with the percent Latino in the state, causing instability (i.e., inflated standard errors) when both variables were included in models. We tested the notion that the key condition under which bilingual emphasis was positively related to achievement was not percent Latino in the state but, rather, Title III funding. Models run with per student Title III funding as a main effect, and in interaction with bilingual policy emphasis, did not show significant interaction effects.

In our final analysis, we examined the relationship between bilingual emphasis in state LIEPs and the achievement gaps between Latino students who 
are both EL and meet criteria for free or reduced lunch and their Latino non$\mathrm{EL} /$ non-lunch eligible peers $(\mathcal{N}=31$ states for reading, $\mathcal{N}=32$ states for mathematics, $\mathcal{N}=28$ states for science). Consistent with the results in our primary analyses, OLS regressions including the bilingual emphasis of state LIEPs alone suggest that achievement disparities between Latino fourth graders with and without the risk factors of EL status and lunch program eligibility are generally wider in states with stronger bilingual emphasis and a larger percentage of Latinos (i.e., significantly positive regression coefficient $b$ ). The disparity, however, narrows in the context of both stronger bilingual emphasis and higher proportion of Latinos in the population (see table 5).

To illustrate these findings, the achievement disparity between Latino ELs who receive free or reduced lunch and their Latino non-EL peers who do not qualify for free or reduced lunch is lower in a state like New Mexico (the most Latino-dense state with the most additive LIEP policy) by approximately two points in reading (approximately .05 of a standard deviation), four points in mathematics $(\approx .15 \mathrm{SD})$, and six points $(\approx .17 \mathrm{SD})$ in science compared to the disparities in a similarly dense state with the most restrictive LIEP. Although the magnitudes of the gaps are relatively small across subject areas, there is evidence that state LIEPs are related to achievement for all Latinos (see López and McEneaney 2012). Nevertheless, the consistency of these results to those shown in table 4 analytically undercuts the notion that state-level differences in curriculum might be driving this pattern.

\section{Discussion}

In consideration of evidence that state policies have more influence on ELs' achievement on NAEP than schools (Rumberger and Tran 2010), and the dearth of research conducted in settings with lower (but growing) proportions of Latino ELs, we examined state LIEPs against Latino population changes in all states. We also examined the relationship between LIEPs and fourthgrade Latino ELs' achievement in reading, mathematics, and science. Consistent with prior work, the findings presented here suggest that a state's bilingual emphasis is associated with Latino ELs' achievement in states with high proportions of Latinos. Many of these states with relatively larger numbers of Latino ELs, however, also have a much longer history of attempting to meet the needs of Latino ELs than states that have only recently witnessed a surge in their Latino EL student population - though there are exceptions.

In the present study, using the reported coefficients in table 4, bilingual LIEPs are associated with higher achievement outcomes than LIEPs that do not use students' native language, once a state has reached an average threshold of close to $20 \%$ of its population identifying as Latino (16\% for reading, $13 \%$ 


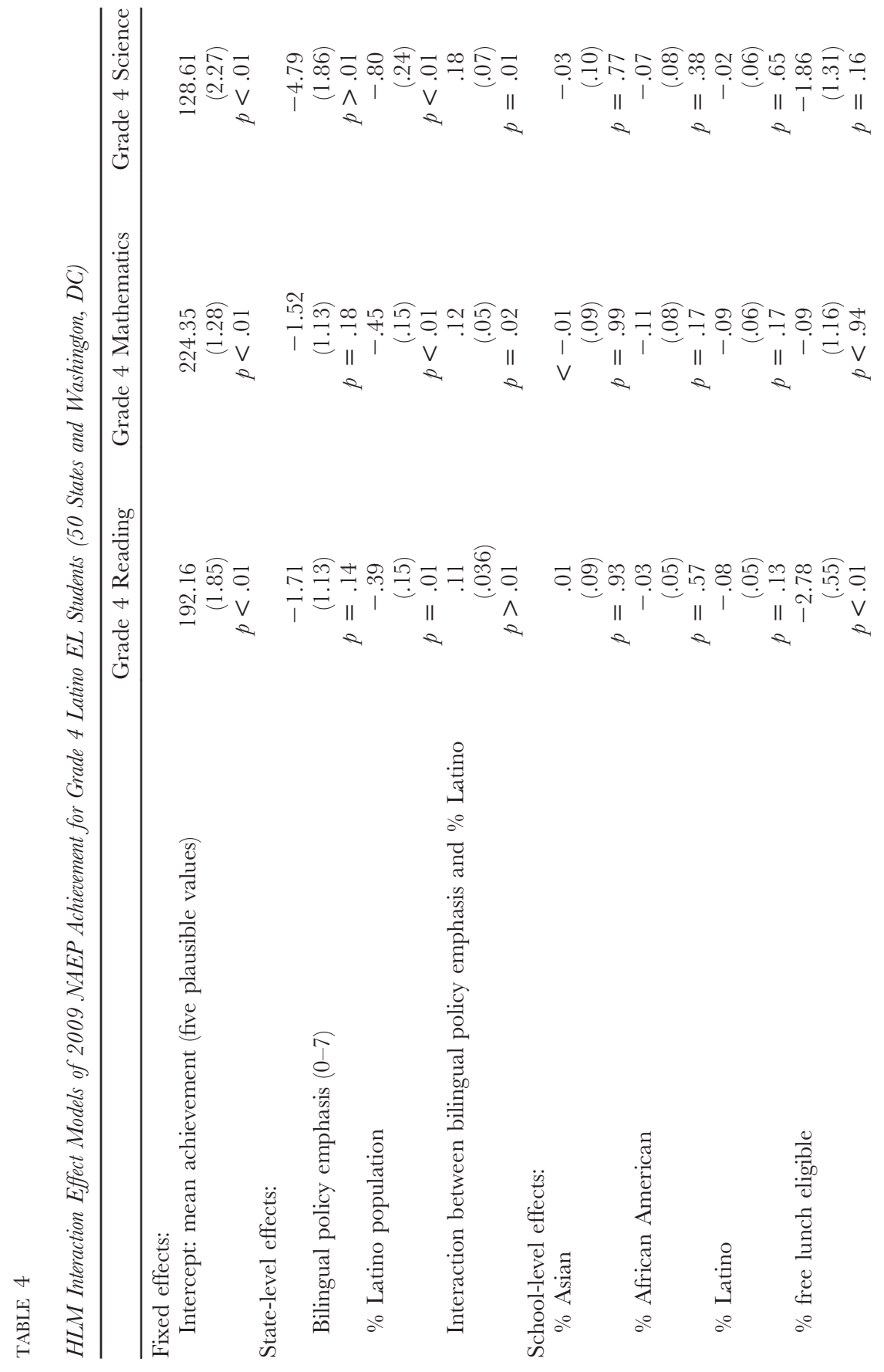




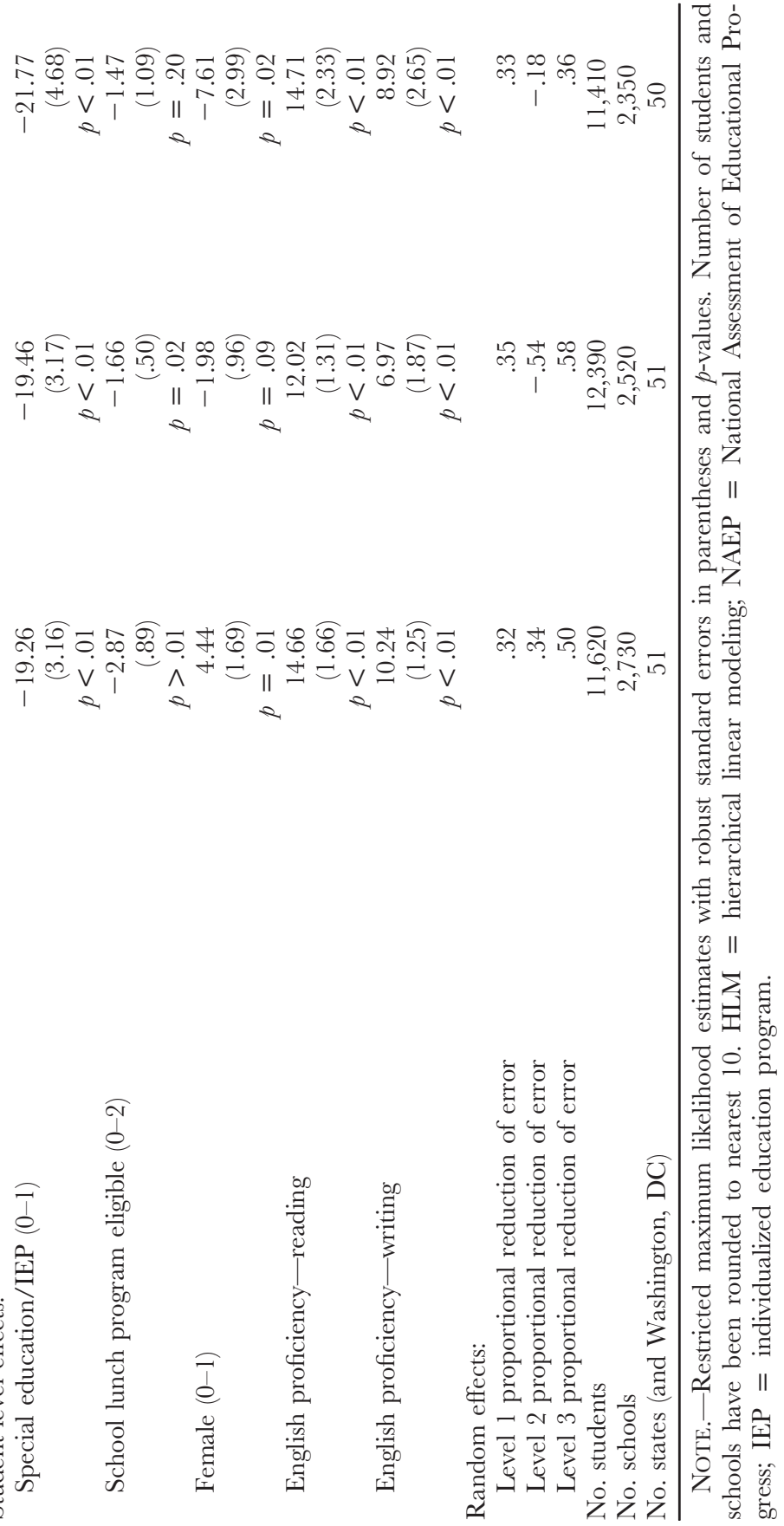




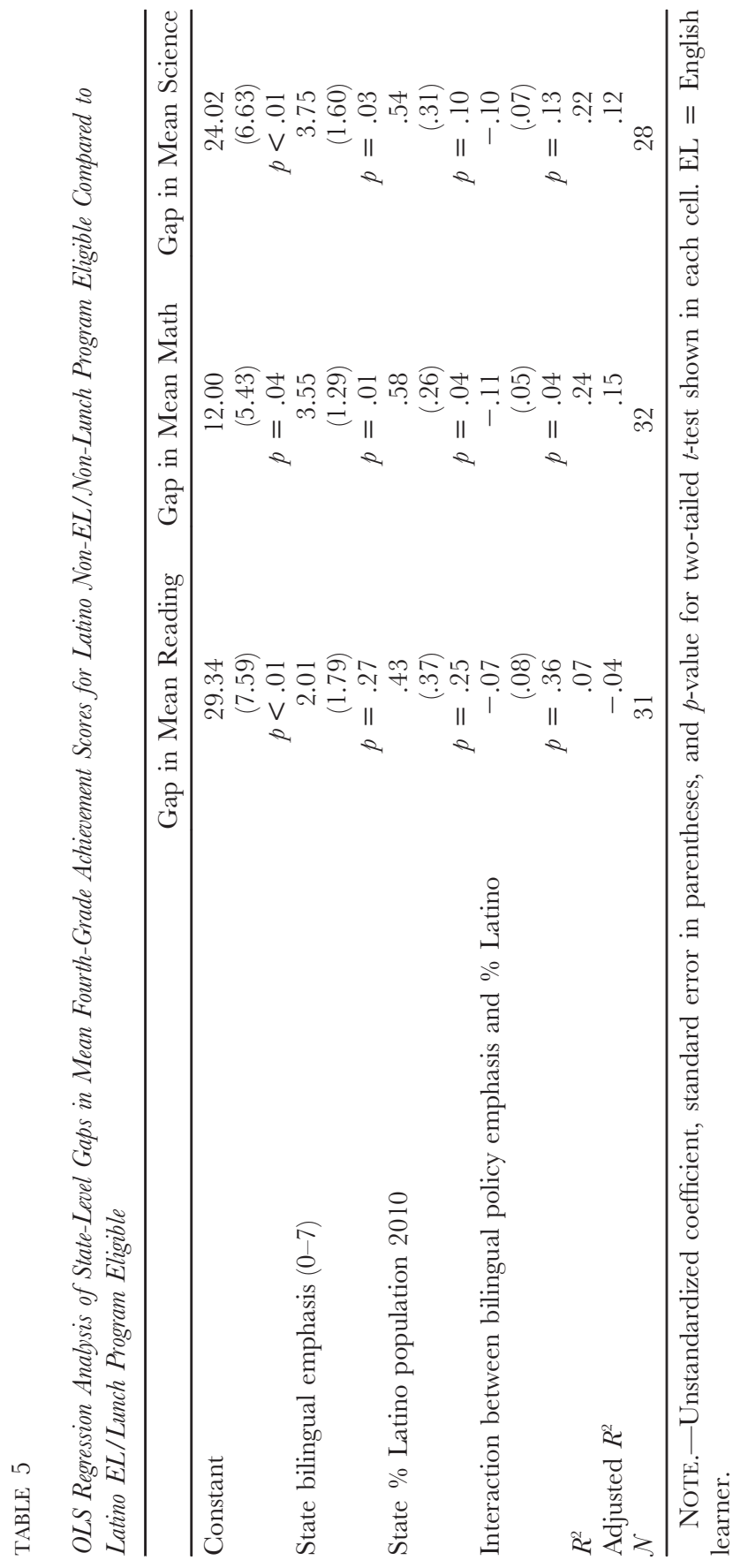

This content downloaded from 128.119.144.192 on September 13, 2016 11:13:45 AM All use subject to University of Chicago Press Terms and Conditions (http://www.journals.uchicago.edu/t-and-c). 
for mathematics, and $27 \%$ for science). Notably, states who have met (and surpassed) this threshold include New Mexico (45\%), California (37\%), Texas $(36 \%)$, Arizona (31\%), Nevada (26\%), Florida (21\%), and Colorado $(20 \%)$ - all states with established policies on meeting the needs of ELs, albeit with varying approaches. New Mexico and Texas are both favorable toward bilingual LIEPs; Nevada, Florida, and Colorado are more flexible in terms of the kind of LIEP schools can use; and California and Arizona restrict the availability of bilingual LIEPs either on the basis of parental demand (California) or if ELs have demonstrated English proficiency (Arizona). It is important to note, however, that although the findings in the NAEP analyses reflect current Latino populations, many states' bilingual LIEP policies have been in place for close to 4 decades - implemented when the Latino populations were substantially lower than they are today. To illustrate, the Latino population in Illinois and New Jersey was approximately 4\% of the total state population in 1970 (see table 2), but both states adopted bilingual LIEPs in the mid-1970s (see appendix). It is only in the coming years that both states are likely to meet the $20 \%$ threshold. Thus, the findings do not suggest states need not consider bilingual LIEPs if the proportion of the Latino population is lower than 20\%; states with current policies that are associated with more favorable outcomes for Latino ELs have had the policies in place long before they reached the threshold.

Although some states will likely meet the threshold in the coming years (see table 2), the rest would take many more years to reach the minimum density to make it more feasible to implement bilingual LIEPs. However, within most states, there are Latino EL-dense counties. Indeed, even though a state policy may reflect the lower proportion of Latino ELs in a state, each state should consider the demographics that may suggest a bilingual LIEP is in best interest of their growing population. To illustrate, Massachusetts has a relatively lower proportion of Latinos (close to 9\%). Yet, two counties, Essex and Hampden, are already at the threshold (US Census Bureau, n.d.). An even closer inspection reveals that 84 school districts already meet or exceed the threshold, with a third of those exceeding $50 \%$. Considering that Massachusetts has close to 31,000 Latino ELs, with prior research indicating that Latino ELs tend to attend schools where they are a majority of the school population (Fry 2008), the threshold found in the present study is likely an exceedingly conservative estimate. Another state, Wisconsin, continues to reflect a bilingual LIEP despite its relatively lower Latino population (5\%). Nevertheless, the Milwaukee Public School district grew from 16\% Latino students in 2000 to $23 \%$ in 2010, and their EL population also grew from 6\% to $11 \%$ in the same decade (Milwaukee Public Schools 2011). Indeed, the growth of ELs in states without a prior history of EL presence is so substantial that the National Clearinghouse for En- 
glish Language Acquisition now reports additional information for the top 10 school districts with the highest EL growth.

A review of the policies on LIEPs for each of the 50 states and the District of Columbia reveals that, to date, 13 states have no mandate to ensure schools meet the needs of ELs. Most of the states that currently have no mandate, however, are among those that have experienced the largest growth of Latino EL student populations in the past decade (see table 2). South Carolina and South Dakota, for example, have witnessed a growth of their Latino EL population of more than $800 \%$ and $600 \%$, respectively, since 1970 . It is possible that states without policies have a paucity of resources to implement LIEPs that emphasize bilingual methods, limiting the extent to which these policies can be implemented. It is important to consider, however, that all Title III funds are allocated to meet the needs of ELs. Since 1974, funding has also been allocated specifically for capacity building. Thus, all states have the responsibility to consider evidence regarding LIEPs and support their school districts accordingly (with knowledge about demographic patterns) to meet the needs of their students.

In reviewing LIEPs of some of the states with a longer history of Latino presence, policies sometimes reflect the need to consider infrastructure and feasibility by explicitly stating the threshold wherein bilingual LIEPs should be implemented. For example, Alaska requires a minimum of eight ELs who share a native language (but also affirms "nothing in this section precludes a bilingual-bicultural education program from being provided for less than eight pupils in a school"; see Alaska Statutes, Title 14, Chap. 30, Sec. 400: Bilingualbicultural education, par. 1), whereas Illinois, New Jersey, New York, and Texas require 20 students who share a native language to implement a bilingual LIEP - although there is also variability across these states in terms of whether the minimum number of students are to be found in one particular school or across a particular district or LEA. Among the aforementioned states, some also explicitly include a caveat that bilingual LIEPs are required but only when staffing is available. Thus, the absence of the relationship between bilingual emphasis in state LIEPs and achievement for Latino ELs in some of the states with relatively lower proportions of Latinos does not suggest that the LIEPs are not effective but that the state may not yet have the number of ELs that provide a rationale to implement bilingual LIEPs effectively. Indeed, a state could very well have a policy in place for bilingual LIEPs, but without the appropriately trained personnel, implementation proves difficult. Nevertheless, the growth of Latino ELs has been a documented, steady trend for the past 4 decades. This suggests that even lower-density states should consider policies that will be most effective for their growing student population and prepare accordingly for the appropriate implementation that will be required. Indeed, policies that are 
explicit in supporting bilingual LIEPs also implicitly reflect states' commitment to providing assistance to school districts.

In many states, school districts are responsible for building capacity in terms of curriculum, staff, and resources to meet the needs of ELs. Some states with a longer history of ELs and policies that are explicitly supportive of bilingual LIEPs, however, have implemented statewide efforts to build capacity (Tenenbaum and Anderson 2010). For example, New York, a state that mandates bilingual education in cases where a minimum number of students is met and sufficient staffing is available, "sponsors five 1-day teacher institutes throughout the school year, and teachers are also provided with tuition assistance to earn their English as a Second Language (ESL) or bilingual certification" (Tenenbaum and Anderson 2010,10). States that have experienced a surge in their EL populations would have much to gain from examining how states like New York have promoted capacity building for staffing and curricula at the state level, particularly because New York, along with several other states (see table 2), considers the nuances across school districts that would determine whether bilingual education or other kinds of LIEPs would best serve ELs. Indeed, most LIEPs that favor bilingual education do not mandate one LIEP in all cases but take into consideration the needs of students and whether staffing is sufficient (see appendix).

Notably, since 2001, Title III has not only provided funding to states for the implementation of LIEPs but has also required the evaluation of ELs' performance. Although seemingly consistent with the third prong of Castañeda, the evaluation of ELs' progress in English acquisition and achievement outcomes is examined at the school-district level, with consequences for failing to meet adequate progress determined by each state (see Tanenbaum and Anderson 2010). Although these types of accountability structures are believed to promote practices that ensure ELs' needs are met (Tanenbaum and Anderson 2010), assessment practices are not without issues (see Abedi 2004). Nevertheless, when states allow school districts or local education agencies to determine the LIEPs used in their schools, as would be the case in the 13 states that currently have no LIEP policy, it is possible that consequences for inadequate academic progress among ELs can promote an evaluation of the LIEPs chosen. Without state-level support, however, even empirically supported LIEPs may not be implemented in ways that can address ELs' needs.

In other cases, such as when a LIEP is determined at the state level, the sanctions applied to school districts may be applied more appropriately to a state. For example, even though Arizona has not met the criteria for adequate progress of ELs in $50 \%$ to $75 \%$ of all districts for at least 2 years (see Tanenbaum and Anderson 2010), it is school districts that are held accountable for ELs' lack of adequate progress rather than the state's policy on LIEPs. Given the 
lack of empirical support for Arizona's SEI, the declining achievement among Latino ELs (García et al. 2010), and the funding issues that have been at the center of Flores $v$. Arizona, it is clear that the state is not in compliance with any of the Castañeda prongs. Nevertheless, because of the accountability framework reflected in NCLB, Arizona will continue to fault school districts for ELs' lack of progress rather than their own policies while remaining eligible for Title III funding to support and build capacity for SEI in schools.

In consideration of the Castañeda criteria and empirical evidence, modifications at the federal and state levels are necessary to ensure compliance with the EEOA and the Court's decision in Lau v. Nichols. Although there are many states that allow school districts or local education agencies to select a particular LIEP, the current accountability system allows states to blame school districts for failing to meet the needs of ELs when funding to build capacity is limited, as is state-level support (Tenenbaum and Anderson 2010). Other states are explicit in the LIEPs allowed but impose sanctions on school districts despite evidence that it is the LIEPs that are at fault for failing to meet the needs of ELs. To ensure Title III funds are allocated in ways that will meet the needs of ELs, states should be required to comply with all three Castañeda prongs. First, states should be required to explicitly state the ways in which ELs will be provided with an equitable education (i.e., explicit LIEPs) and demonstrate that the LIEPs espoused at the state level have empirical support. Accordingly, the disbursement of Title III funds to support capacity building for LIEPs should be contingent on the extent to which a state's LIEPs reflect empirical, rather than ideological, evidence, as well as the extent to which states are providing support. To further ensure that capacity-building Title III funds are aimed at LIEPs that demonstrate promise for ELs, evaluation of the LIEPs used in school districts should be required.

Empirical evidence suggests that states should support bilingual LIEPs when feasible (e.g., when a minimum number of students share a native language within a grade level) and promote capacity building at the state level. Given that Title III funding is often insufficient, particularly in states with a more recent history of needing to meet the needs of ELs (Tenenbaum and Anderson 2010), it is possible that the federal funding formulas require reassessment so that states in most need of building capacity are provided with adequate funds. Currently, the funding system may not provide funding where it is needed most. As an example, California - a state with a long history of ELshas recently had to reallocate unused Title III funds (California Department of Education 2010), whereas states with a relatively recent growth of ELs struggle to provide sufficient funding (Tenenbaum and Anderson 2010). By only funding states whose LIEPS are based on empirical evidence, requiring both an evaluation of state-level support and the effectiveness of LIEPs in the allocation of capacity-building funding, and providing states in the earliest stages 
of capacity building with funds that reflect the length of time they have had to build capacity, federal policy can support state-level policy in meeting the needs of our growing EL populations.

\section{Notes}

This research was supported by a grant from the American Educational Research Association, which receives funds for its AERA Grants Program from the National Science Foundation under NSF grant DRL-0941014. Opinions reflect those of the authors and do not necessary reflect those of the granting agencies. The manuscript has been cleared for dissemination by the Institute of Educational Sciences/National Center for Educational Statistics. The authors wish to thank Laura Geronime for her assistance.

1. Researchers and states use various labels for the kind of instruction aimed at increasing English proficiency among ELs. Instructional models, language acquisition models, language policies, and others are used interchangeably. We use the language reflected in reports for Adequate Yearly Progress submitted to the US Department of Education.

2. We examined the proportion of Latinos rather than the proportion of Latino ELs in each state for two key reasons. The first is the absence of detailed data regarding the proportion of Latino ELs in all states in the 1970s, limiting the extent to which we could examine patterns from the 1970s, when the Latino population began to grow (Krogstad and Keegan 2014), and the present. The second is that clearly not all Latinos speak Spanish at home (a key indicator of students' EL status); however, the correlation between the proportion of Latino ELs in a state and their Latino population overall is exceptionally strong, with $r=.95$ using National Clearinghouse for English Language Acquisition (NCELA) data for the proportion of Latino ELs in a state and US Census Bureau information regarding the proportion of Latinos in 2009.

3. Here, we focus on the largest EL population in the United States, Latinos. Although there are a vast number of languages represented by US ELs, the ways in which the needs of heterogeneous language groups are met differ substantially from those who are homogeneous, as would be the case in both dual language and bilingual approaches.

4. The ballot initiative in California used the term "Sheltered English Immersion," whereas the ballot measure in Arizona used the term "Structured English Immersion." The guidelines for both are nearly indistinguishable and used interchangeably as SEI (Parrish et al. 2006).

5. Proposition 227 is the California ballot initiative that replaced bilingual education with SEI in 1998. The author of Proposition 227, Ron Unz, also authored Proposition 203 in Arizona that replaced bilingual education with SEI in 2001 and Question 2 in Massachusetts in 2002.

6. Title III is the federal funding base for language acquisition programs.

7. To examine how LIEPs inform Latino EL achievement using cross-sectional data, it would be ideal to analyze multiple years of NAEP. However, analyses using data sets

MAY 2015 


\section{Language Instruction Educational Programs and Academic Achievement}

prior to the 2003 NAEP administration would exclude many states because of sampling issues with Latino ELs. Since 2003, only the 2005 and 2009 administrations of NAEP have included science. The 2005 science assessment, however, is not comparable to 2009 because of dramatic changes to the framework.

\section{References}

Abedi, Jamal. 2004. "The No Child Left Behind Act and English Language Learners: Assessment and Accountability Issues." Educational Researcher 33 (1): 4-14.

Arizona Department of Education. 2007. "Arizona English Language Learners Task Force: Research Summary and Bibliography for Structured English Immersion Program Models," 1, https://www.azed.gov/wp-content/uploads/PDF /modelcomponentresearch.pdf.

August, Diane, and Kenji Hakuta, eds. 1997. Improving Schooling for Language-Minority Children. Washington, DC: National Academy Press, http://www.nap.edu/openbook .php?record_id $=5286 \&$ page $=\mathrm{R} 1$.

August, Diane, and Timothy Shanahan, eds. 2006. Developing Literacy in SecondLanguage Learners: Report of the National Literacy Panel on Language-Minority Children and Touth. Mahwah, NJ: Lawrence Erlbaum.

Batalova, Jeanne, and Margie McHugh. 2010. Number and Growth of Students in US Schools in Need of English Instruction. Washington, DC: Migration Policy Institute, http:// www.ncela.gwu.edu/files/uploads/NCELAFactsheets/EL_Languages_2011.pdf.

California Department of Education. 2010. "Elementary and Secondary Education Act, Title III, Part A, Reallocation Process." California Department of Education, Sacramento, http://www.cde.ca.gov/sp/el/t3/.

Callahan, Rebecca M. 2005. "Tracking and High School English Learners: Limiting Opportunity to Learn." American Educational Research fournal 42 (2): 305-28.

Capps, Randy, Michael Fix, Julie Murray, Jason Ost, Jeffrey S. Passel, and Shinta Herwantoro. 2005. The New Demography of America's Schools: Immigration and the No Child Left Behind Act. Washington, DC: Urban Institute.

Carnoy, Martin, and Susanna Loeb. 2002. "Does External Accountability Affect Student Outcomes? A Cross-State Analysis." Educational Evaluation and Policv Analvsis 24 (4): 305-31.

Clark, Kevin. 2009. "The Case for Structured English Immersion.” Educational Leadership 66 (7): 42-46.

Collier, Virginia P., and Wayne P. Thomas. 2004. "The Astounding Effectiveness of Dual Language Education for All." NABE Journal of Research and Practice 2 (1): 1-20.

Crawford, James. 1997. "The Campaign against Proposition 227: A Post Mortem." Bilingual Research fournal 21 (1): 1-29.

Cummins, Jim. 1992. "Bilingual Education and English Immersion: The Ramirez Report in Theoretical Perspective." Bilingual Research foumal 16 (1-2): 91-104.

Finkel, Steven E. 1995. Causal Analysis with Panel Data, vol. 105. Thousand Oaks, CA: Sage.

Fry, Richard Allan. 2008. The Role of Schools in the English Language Learner Achievement Gap. Washington, DC: Pew Hispanic Center, http://www.pewhispanic.org/2008 /06/26/the-role-of-schools-in-the-english-language-learner-achievement-gap/. 


\section{López, McEneaney, and Nieswandt}

Gándara, Patricia. 2012. "Learning English in California: Guideposts for the Nation." In The New Immigration: An Interdisciplinary Reader, ed. Carola Suarez-Orozco, Marcelo Suarez-Orozco, and Desiree Baolian Qin-Hilliard. New York: Routledge.

Gándara, Patricia, and Barbara Merino. 1993. "Measuring the Outcomes of LEP Programs: Test Scores, Exit Rates, and Other Mythological Data." Educational Evaluation and Policy Analvsis 15 (3): 320-38.

Gándara, Patricia, and Gary Orfield. 2012. "Segregating Arizona's English Learners: A Return to the 'Mexican Room'?" Teachers College Record 114 (9): 1-27.

Gándara, Patricia, and Russell Rumberger. 2009. "Immigration, Language, and Education: How Does Language Policy Structure Opportunity?" Teachers College Record 111 (3): 750-82.

Garcia, Eugene E., and Ellen C. Frede. 2010. Young English Language Learners: Current Research and Emerging Directions for Practice and Policy. New York: Teachers College Press.

Garcia, Eugene, Kerry Lawton, and Eduardo H. Diniz de Figueiredo. 2010. "The Education of English Language Learners in Arizona: A Legacy of Persisting Achievement Gaps in a Restrictive Language Policy Climate." UCLA Civil Rights Project, Los Angeles, http://civilrightsproject.ucla.edu.

Gibson, Campbell, and Kay Jung. 2002. "Historical Census Statistics on Population Totals by Race, 1790 to 1990, and by Hispanic Origin, 1970 to 1990, for the United States, Regions, Divisions, and States.” US Census Bureau, Washington, DC, https:// www.census.gov/population/www/documentation/twps0076/twps0076.html.

Hayes, Andrew F., and Klaus Krippendorff. 2007. "Answering the Call for a Standard Reliability Measure for Coding Data." Communication Methods and Measures 1 (1): 77-89.

Horsford, Sonya D., and Carrie Sampson. 2013. "High ELL-Growth States: Expanding Funding Equity and Opportunity for English Language Learners." Voices in Urban Education 37:47-54.

Iacobucci, Dawn, Kent Grayson, and Roland Rust. 2001. "Interrater Reliability." Fournal of Consumer Psychology 10 (1-2): 71-73.

Johnson, Eugene G. 1989. "Considerations and Techniques for the Analysis of NAEP Data." Fournal of Educational and Behavioral Statistics 14 (4): 303-34.

Krashen, Stephen D. 1997. "A Researcher's View of Unz," http://www.languagepolicy .net/archives/Krashenl.htm.

Krogstad, Jens M., and M. Keegan. 2014. From Germany to Mexico: How America's Source of Immigrants Has Changed over a Century. Washington, DC: Pew Research Center, http://www.pewresearch.org/fact-tank/2014/05/27/a-shift-from-germany-to -mexico-for-americas-immigrants/.

Lambert, Wallace E. 1985. "Some Cognitive and Sociocultural Consequences of Being Bilingual." In Perspectives on Bilingualism and Bilingual Education: International Dimensions of Bilingual Education, ed. James E. Alatis and John J. Staczek. Washington, DC: Georgetown University Press.

Lee, Jaekyung. 2006. "Tracking Achievement Gaps and Assessing the Impact of NCLB on the Gaps: An In-Depth Look into National and State Reading." Research report, Civil Rights Project at Harvard University, Cambridge, MA.

Linton, April. 2004. "A Critical Mass Model of Bilingualism among US-Born Hispanics." Social Forces 83 (1): 279-314.

López, Francesca, and Elizabeth McEneaney. 2012. "English Language Learners and State Language Acquisition Policies.” Educational Policy 26 (3): 418-64.

MAY 2015 
Lord, Frederic M. 1980. Applications of Item Response Theory to Practical Testing Problems. Hillsdale, NJ: Lawrence Erlbaum.

Luke, Douglas A. 2004. Multilevel Modeling, vol. 143. Thousand Oaks, CA: Sage.

Lyons, James J. 1990. "The Past and Future Directions of Federal Bilingual Education Policy." Annals of the American Academv of Political and Social Science 508 (1): 66-80.

Maas, Cora J. M., and Joop J. Hox. 2004 "Robustness Issues in Multilevel Regression Analysis." Statistica Neerlandica 58 (2): 127-37.

Milwaukee Public Schools. 2011. "District Report Card.” Milwaukee Public Schools, http://www2.milwaukee.k12.wi.us/acctrep/district_data_report_card_1011.pdf.

Mislevy, Robert J., Eugene G. Johnson, and Eiji Muraki. 1992. "Scaling Procedures in NAEP." Fournal of Educational and Behavioral Statistics 17 (2): 131-54.

Mok, Miranda. 1995. "Sample Size Requirements for 2-Level Designs in Educational Research." Multilevel Modelling Newsletter 7 (2): 11-15.

Moran, Rachel F. 2011. "Equal Liberties and English Language Learners: The Special Case of Structured Immersion Initiatives." Howard Law Fournal 54 (2): 397-424.

NAEP (National Assessment of Educational Progress). 2010. NAEP-Mathematics 2009: Inclusion Rates. Washington, DC: National Assessment of Educational Progress, http://nces.ed.gov/nationsreportcard/about/inclusion.asp.

National Center for Education Statistics. 2013. "English Language Learners." In The Condition of Education 2013 (NCES 2013-037). Washington, DC: National Center for Education Statistics, http://nces.ed.gov/fastfacts/display.asp?id = 96 .

Neuendorf, Kimberly. 2002. The Content Analysis Guidebook. Thousand Oaks, CA: Sage.

NMPED (New Mexico Public Education Department). 2004. "Technical Assistance Manual." Bilingual Multicultural Education Bureau, New Mexico Public Education Department, Santa Fe, http://www.ped.state.nm.us/BilingualMulticultural/dl09 /fullPackageBilingualTAM.pdf.

Parrish, Tom B., Amy Merickel, María Perez, Robert Linguanti, Miguel Socias, Angeline Spain, and Danielle Delancey. 2006. "Effects of the Implementation of Proposition 227 on the Education of English Learners, K-12: Findings from a Five-Year Evaluation." Final Report for AB 56 and AB 116, American Institutes of Research, Washington, DC.

Porfeli, Erik, Chuang Wang, Robert Audette, Ann McColl, and Bob Algozzine. 2009. "Influence of Social and Community Capital on Student Achievement in a Large Urban School District." Education and Urban Society 42 (1): 72-95.

Ramirez, J. David, Sandra D. Yuen, Dena R. Ramey, and David J. Pasta. 1991. Final Report: Longitudinal Study of Structured Immersion Strategy, Early-Exit, and Late-Exit Transitional Bilingual Education Programs for Language-Minority Children. San Mateo, CA: Aguirre International.

Raudenbush, Stephen W., and Anthony S. Bryk. 2002. Hierarchical Linear Models: Applications and Data Analysis Methods, vol. 1. Thousand Oaks, CA: Sage.

Rolstad, Kellie, Kate Mahoney, and Gene V. Glass. 2005. "The Big Picture: A MetaAnalysis of Program Effectiveness Research on English Language Learners." Educational Policy 19 (4): 572-94.

Rossell, Christine H. 2002. Dismantling Bilingual Education Implementing English Immersion: The California Initiative. San Francisco: Public Policy Institute of California.

Rumberger, Russell W., and Loan Tran. 2010. "State Language Policies, School Language Practices, and the English Learner Achievement Gap." In Forbidden Language: English Learners and Restrictive Language Policies, ed. Patricia Gándara and Megan Hopkins. New York: Teachers College Press. 
Skinner, Chris J., David Holt, and T. M. Fred Smith, eds. 1989. Analysis of Complex Surveys. Chichester: Wiley.

Slavin, Robert E., and Alan Cheung. 2005. "A Synthesis of Research on Language of Reading Instruction for English Language Learners." Review of Educational Research 75 (2): 247-84.

Slavin, Robert E., Nancy Madden, Margarita Calderón, Anne Chamberlain, and Megan Hennessy. 2010. "Reading and Language Outcomes of a Five-Year Randomized Evaluation of Transitional Bilingual Education." Best Evidence Encyclopedia, April 22, http://www.bestevidence.org/word/bilingual_education_Apr_22_2010.pdf.

Snijders, Tom A. B., and Roel J. Bosker. 1999. Multilevel Analysis: An Introduction to Basic and Advanced Multilevel Modeling. London: Sage.

Solano-Flores, Guillermo, and Elise Trumbull. 2003. "Examining Language in Context: The Need for New Research and Practice Paradigms in the Testing of EnglishLanguage Learners." Educational Researcher 32 (2): 3-13.

Stewner-Manzanares, Gloria. 1988. "The Bilingual Education Act: Twenty Years Later." New Focus, Occasional Papers in Bilingual Education 6:2-8.

Stoneberg, Bert D. 2007. "Using NAEP to Confirm State Test Results in the No Child Left Behind Act." Practical Assessment Research and Evaluation 12 (5): 1-10.

Tenenbaum, Courtney, and Lindsay Anderson. 2010. "Title III Accountability and District Improvement Efforts: A Closer Look.” ESEA Evaluation Brief: The English Language Acquisition, Language Enhancement, and Academic Achievement Act, US Department of Education, ED-04-CO-0025/0017.

Tong, Fuhui, Rafael Lara-Alecio, Beverly Irby, Patricia Mathes, and Oi-man Kwok. 2008. "Accelerating Early Academic Oral English Development in Transitional Bilingual and Structured English Immersion Programs." American Educational Research Zournal 45 (4): 1011-44.

Umansky, Ilana, and Sean Reardon. 2014. "Reclassification Patterns among Latino English Learner Students in Bilingual, Dual Immersion, and English Immersion Classrooms." American Educational Research Fournal 51 (5): 879-912.

US Census Bureau. n.d. State and County QuickFacts. Washington, DC: US Census Bureau, http://quickfacts.census.gov/qfd/states/25/25009.html.

US Census Bureau. 2009. Current Population Survey, Table 4b: Reported Voting and Registration of the Voting-Age Population, by Sex, Race and Latino Origin, for States: November 2008. Washington, DC: US Census Bureau.

US Census Bureau. 2012. American Community Survey. Washington, DC: US Census Bureau, http://www.census.gov/acs/www/.

US Department of Justice. n.d. Types of Educational Opportunities Discrimination. Washington, DC: US Department of Justice, http://www.justice.gov/crt/about/edu/types.php.

Wiley, Terrence G., and Wayne E. Wright. 2004. "Against the Undertow: LanguageMinority Education Policy and Politics in the 'Age of Accountability.'” Educational Policv 18 (1): 142-68.

Wilson, William Julius. 1987. The Truly Disadvantaged: The Inner City, the Underclass, and Public Policy. Chicago: University of Chicago Press.

Wright, Wayne E. 2005. "Evolution of Federal Policy and Implications of No Child Left Behind for Language Minority Students." Policy Brief, Education Policy Studies Laboratory Language Policy Research Unit, Arizona State University, Tempe, http://epsl.asu.edu/epru/documents/EPSL-0501-101-LPRU.pdf.

Wright, Wayne E., and Chang Pu. 2005. "Academic Achievement of English Language Learners in Post-Proposition 203 Arizona.” Policy brief, Education Policy 
Language Instruction Educational Programs and Academic Achievement

Studies Laboratory Language Policy Research Unit, Arizona State University, Tempe, http://epsl.asu.edu/epru/documents/EPSL-0509-103-LPRU.pdf.

Zehr, Mary Ann. 2010. "Bilingual Mandate Challenges Chicago's Public Preschools." Education Week 30 (1): 1-2.

Zwick, Rebecca. 1992. "Statistical and Psychometric Issues in the Measurement of Educational Achievement Trends: Examples from the National Assessment of Educational Progress." Journal of Educational and Behavioral Statistics 17 (2): 205-18. 